\title{
Correction to: A genealogy of Florence Nightingale, Charles Darwin, Francis Galton and Francis Ysidro Edgeworth with special reference to their Italian connections and an annexe on Beatrice Webb and Charles Booth
}

\section{Richard William Farebrother ${ }^{1}$}

Accepted: 11 September 2017 / Published online: 8 November 2017

(C) Springer-Verlag GmbH Germany 2017

\section{Correction to: Stat Methods Appl (2013) 22:391-402 DOI 10.1007/s10260-013-0231-x}

(a) On page 393, replace the final word of

"In 1794 [W2] John Wedgwood married [A3] Louisa Jane (Jenny) Allen. They had several children including:"

by a full stop.

(b) On page 393, amend the next three entries to read:

“[W32] Josiah Wedgwood III (1795-1880) who married [D11] Caroline Sarah Darwin in 1837 [not 1831]. They had four daughters including:

[W32+] Margaret Susan Wedgwood (1843-1937) ...

[W32++] Ralph Vaughan Williams (1872-1958), composer." and move this block to follow the entry:

"[W31] Emma Wedgwood (1808-1896) ..."

(c) Make the consequential changes to the entry for [D11] Caroline Sarah Darwin on page 394 and in the third paragraph of Sect. 4 on page 399.

(d) On page 399, divide the third paragraph of Sect. 4 after "Etruria" and attach the second part of this paragraph to the second paragraph of Sect. 4.

The online version of the original article can be found under https://doi.org/10.1007/s10260-013-0231-x.

$\bigotimes$ Richard William Farebrother

r.w.farebrother@manchester.ac.uk

111 Castle Road, Bayston Hill, Shrewsbury, UK 
(e) On page 399, delete the fourth paragraph of Sect. 4 beginning "As two brothers had married two sisters ..." and substitute:

"If two brothers had married two sisters as here in the second generation, or if a brother and a sister had married a sister and a brother as here in the third generation [and also on page 395 in the final paragraph of Sect. 2.6], then their children would have had all four grandparents in common."

(f) On page 399, in the fifth paragraph of Sect. 4 replace "suggest that Emma" by "suggest that the children of Emma" and delete the second part of this second sentence from"whilst ..."

(g) On page 401, in the last paragraph of Sect. 5 beginning

"By contrast, Inglis-Jones (1971-1972) mentions Sydney Smith's Slater cousins on three occasions, one of whom, Mary Slater, married ..."

should read:

"By contrast, Inglis-Jones (1971-1972) mentions Rev. Sydney Smith on numerous occasions. Further, one of his cousins, Mary Slater, married ..."

(h) There are also several minor spelling errors which I shall not trouble to note. The most significant are "for Drew read Drewe" in the first line of page 400 and "For C. M. Trevelyan read G. M. Trevelyan" in the Summary on page 390 and in the first reference on page 402 . 